\title{
SERVICE ENCOUNTER DI YAYASAN NURUL HAYAT SURABAYA
}

\author{
Firyal Afifah Huda, Ahmad Khairul Hakim \\ Universitas Islam Negeri Sunan Ampel Surabaya \\ Afifahvella3@gmail.com
}

\begin{tabular}{l}
\hline \hline Article info: \\
\hline Keyword: \\
Service encounter, \\
Pertemuan layanan, \\
Pelayanan \\
\hline
\end{tabular}

Page: $1-18$

\section{Editorial Office:}

Program Studi Manajemen Dakwah, Fakultas Dakwah dan Komunikasi, UIN Sunan Ampel Surabaya. Jl. Ahmad Yani 117 Surabaya, Jawa Timur, Indonesia.

Email: jurnalilkom@uinsby.ac.id

\begin{abstract}
This study aims to describe the implementation of service encounters at the Nurul Hayat Foundation and the supporting and inhibiting factors in its application. To describe these two problems, the researcher used a qualitative approach with descriptive research type. The data collection techniques used were interviews, observation, and documentation. The results of this study indicate that the application of service encounters takes place in three stages, namely: pre-purchase, service encounter and post-purchase. In its implementation, service encounter support factors include: the use of SOPs as a basis for employees, a special team in monitoring employees on their SOPs, providing call centers, trying to solve any problems quickly, providing training for employees, providing product knowledge books to memorize, requiring customer service always friendly, strives to always be trustworthy in managing the money that has been given by consumers, guarantees consumer data, employees are able to adapt to every consumer who comes, requires cs employees to memorize the names of consumers who are interacting with employees, and have concrete evidence of the building and reviews from consumers. Meanwhile, the inhibiting factors for service encounters include: employees have odd jobs which can affect the service and one main building is inadequate in serving consumers.
\end{abstract}

Penelitian ini bertujuan untuk menggambarkan pelaksanaan service encounter di Yayasan Nurul Hayat serta faktor pendukung dan penghambat dalam penerapannya. Untuk mendeskripsikan kedua permasalahan tersebut, peneliti menggunakan pendekatan kualitatif dengan jenis penelitian deskriptif. Teknik pengumpulan data yang digunakan adalah wawancara, observasi, dan dokumentasi. Hasil penelitian ini menunjukan, bahwa penerapan service encounter melalui tiga tahap, yaitu: pra pembelian,service encounter, dan pasca pembelian. Dalam pelaksanaannya factor pendukung service encounter di antaranya: penggunaan SOP sebagai landasan karyawan, tim khusus dalam memantau karyawan pada SOPnya, menyediakan call center, mengupayakan setiap permasalahan selesai dengan cepat, memberikan training bagi karyawan, memberikan buku product knowledge untuk dihafalkan, mewajibkan custumor service untuk selalu ramah, mengupayakan untuk selalu amanah dalam mengelola uang yang telah diberikan konsumen, menjamin data-data konsumen, karyawan mampu menyesuaikan diri terhadap setiap konsumen yang datang, mewajibkan karyawan cs untuk menghafal nama konsumen yang sedang berinteraksi dengan karyawan, dan mempunyai bukti nyata gedung dan review dari konsumen. Sedangkan, factor penghambat service encounter diantaranya: karyawan mempunyai kerja sambilan yang bisa mempengaruhi pelayanan dan salah satu gedung utama tidak memadai dalam melayani konsumen. 


\section{Pendahuluan}

Saat ini, teknologi berkembang secara cepat di Indonesia. Jadi, masyarakat Indonesia semakin dimudahkan dengan adanya perkembangan teknologi, sehingga teknologi telah menjadi kebutuhan masyarakat Indonesia. Perkembangan teknologi internet telah membuat masyarakat Indonesia semakin di mudahkan di dalam kehidupan sehari-hari. Hal ini di karenakan, internet memberikan segala hal pengetauhan ataupun kebutuhan yang di butuhkan oleh masyarakat Indonesia. Oleh karena itu, tidak sedikit perusahaan menggunakan media internet untuk menawarkan produknya.

Setiap perusahaan mempunyai sistem marketing tersendiri dalam perusahaanya. Jadi, perusahaan mempunyai sistem marketing tersendiri dalam perusahaanya, agar konsumen dapat mengetauhi produk yang dijual oleh perusahaan. Sistem marketing tersebut digunakan untuk menawarkan produknya. Jadi, setiap perusahaan mempunyai markerting sendiri sesuai dengan pasarnya, tetapi sebagian perusahaan telah menggunakan internet sebagai media pengelolaan sistem marketing. Pengelolaan sistem sendiri dapat berupa jual beli, bayar membayar, atau media promosi. Oleh karena itu, internet menjadi hal yang terpenting bagi sebagian perusahaan.

Penggunaan internet mempunyai berbagai manfaat bagi keberlangsungan perusahaan. Beberapa perusahaan menggunakan internet untuk mencari konsumen. Jadi, perusahaan dapat mengenalkan produk-produk yang dimiliki, sehingga konsumen dapat mengetauhi karakteristik produk tanpa pergi ke perusahaan. Dengan adanya internet, perusahaan berharap konsumen dapat dimudahkan untuk memiliki produk yang diberikan perusahaan.

Penggunaan internet mempunyai tantang sendiri bagi perusahaan. Jadi, perusahaan memiliki tantangan, apabila perusahaan mempromosikan produknya. Ketika, konsumen ingin membeli produknya melalui internet, maka perusahaan memiliki tantangan untuk memberikan pemahaman terhadap produk yang dijual. Hal ini dikarenakan, konsumen tidak merasakan kekecewaan setelah mendapatkan produknya. Selain itu, pelayanan perusahaan mempunyai peranan penting saat berinteraksi di online. Karena, keputusan konsumen dalam membeli produk perusahaan, pelayanan yang diberikan perusahaan dapat dinilai oleh konsumen. Jika pelayanan yang memudahkan konsumen dalam mendapatkan produk, maka perusahaan dapat mempunyai dampak yang tinggi bagi penjualannya.

Selain memberikan kemudahan bagi konsumen, perusahaan juga diharapkan untuk memberikan kejujuran tentang produk yang dimilikinya. Kejujuran dalam memaparkan produk yang dimiliki ialah keharusan bagi perusahaan. Oleh karena itu, setiap perusahaan perlu menerapkan prinsip tersebut. Jadi, setiap perusahaan perlu menerapkan kejujuran, apabila perusahan ingin menyampaikan produknya melewati online maupun langsung. Jika perusahaan memberikan kejujuran kepada konsumen, maka kondisi produk yang diterima konsumen sesuai dengan penyampaian perusahaan. Jika, kondisi barang yang sampai pada konsumen sesuai, maka konsumen akan menumbuhkan rasa percaya pada perusahaan. Oleh karenaitu, 
perusahaan harus memberikan produk yang berkualitas bagi konsumen.

Apabila perusahaan memberikan kemudahan transaksi dan kejujuran kondisi produk, maka perusahaan juga perlu mempunyai pelayanan yang baik. Pelayanan yang baik ialah pelayanan yang mempunyai kualitas pelayanan. Menurut Kotler, kualitas pelayanan adalah sebuah kinerja yang diberikan oleh seseorang terhadap konsumen. Kualitas pelayanan adalah sebuah konsep dalam kinerja perusahaan untuk memberikan konsumen kepuasan dalam memperoleh jasa ataupun barang yang dibelinya. ${ }^{1}$

Kualitas pelayanan ialah salah satu unsur penting agar konsumen selalu tetap memakai produk yang diberikan perusahaan. Jika perusahaan memberikan kualitas pelayanan yang baik, maka konsumen akan puas saat mendapatkan produknya. Kepuasan konsumen ialah suatu reward bagi perusahaan. Menurut Wright, kepuasan konsumen adalah ungkapan emosional setelah pembelian produk pada suatu perusahaan . Kepuasan konsumen ialah perasaaan hasrat yang telah terpenuhi dari pelayanan yang telah diberikan kepada konsumen. Kepuasan konsumen ialah hal yang dapat dijadikan tolak ukur bagi keloyalan konsumen pada perusahaan.

Loyalitas konsumen dapat membuat konsumen akan menjadi pembeli tetap bagi perusahaan. Menurut hasan, loyalitas

\footnotetext{
${ }^{1}$ Lubis Alfi Syahri dan Andayani Nur Rahma, "Pengaruh Kualitas Pelayanan (Service Quality) Terhadap Kepuasan Pelanggan PT Sucofindo Batam", Business Administration, (Vol 1 No 2 Tahun 2017)

${ }^{2}$ Putri Yulia Larasati Dan Utomo Hardi,"Pengaruh Kualitas Pelayanan Terhadap Loyalitas Pelanggan Dengan Kepuasan Sebagai Variable Intervening
}

konsumen adalah komitmen konsumen saat konsumen percaya pada suatu produk perusahaan dan menjadikan konsumen membeli ulang ataupun berlangganan pada perusahaan. Loyalitas konsumen didukung dengan kesetiaan konsumen menggunakan produk yang dimiliki konsumen. Oleh karena itu, loyalitas konsumen di dapatkan melalui pelayanan yang baik yang di berikan dari perusahan. ${ }^{2}$

Pelayanan yang baik untuk konsumen melalui berbagai macam. Perusahaan jasa mempunyai standart tersendiri dalam melayani konsumennya. Jika perusahaan jasa mempunyai pelayanan yang baik, maka konsumen akan setia dengan produknya. Pelayanan jasa dapat dilakukan melalui service encounter. Menurut Zeithamel, service encounter adalah terjadinya interaksi antara konsumen dengan penyediaan jasa. Service encounter adalah fenomena dimana bertemunya konsemen dengan penyedian jasa dan terjadinya sebuah interaksi. Pelayanan setiap perusahaan adalah salah satuhal penting dalam mempertahankan konsumen. Oleh karena itu, setiap perusahaan perlu untuk terus meningkatkan kualitas pelayanan bagi konsumen. Jika kualitas layanan pada perusahaan jasa terus ditingkatkan, maka konsumen akan tetap menggunakan jasa pada perusahaan tersebut. ${ }^{3}$

Dari penjelasan diatas, penulis ingin meneliti Yayasan Nurul Hayat. Peneliti

(StudiPresepsi Pada Pelanggan Dian Corp Ambarawa), Jurnal Manajemen, (Vol 10 No 19 Tahun 2017).

${ }^{3}$ Panjaitan Effendi Januar Dan Yuliati Ai Lili, "Pengauh Kualitas Pelayanan Terhadap Kepuasan elangganan Pada JNE Cabang Bandung", Jurnal Manajemen, (Vol 11 No 2 Tahun 2016) 
menggunakan Yayasan Nurul Hayat sebagai objek penelitian karena Yayasan Nurul Hayat termasuk sebagai Lembaga zakat yang berkembang dengan pesat. Yayasan Nurul Hayat termasuk sebagai Yayasan zakat terbaik di Indonesia tahun 2018. Saat ini, Lembaga zakat sudah banyak ditemui di Indonesia, tetapi Yayasan Nurul Hayat dapat menjadi Lembaga zakat terbaik di Indonesia tahun 2018. Hal ini dikarenakan, Yayasan Nurul Hayat selalu berupaya untuk memberikan pelayanan yang maksimal kepada konsumen. Yayasan Nurul Hayat selalu berusaha untuk membuat konsumen bahagia menerima pelayanan yang diberikan. Selain itu, Yayasan Nurul Hayat memberikan layanan terbaik bagi masyarakat yang ingin menyalurkan dananya untuk digunakan sebagai zakat. Oleh karena itu, Yayasan Nurul Hayat mempunyai standart pelayanan yang baik saat berinteraksi pada konsumennya.

\section{Kajian Pustaka}

\section{Service encounter}

Service encounter adalah sebuah interaksi layanan dari penyedia jasa kepada konsumen supaya konsumen memiliki ketertarikan untuk memakai jasa yang dimiliki penyedia jasa. Jadi, service encounter menekankan pada interaksi antara konsumen dan penyedia jasa pertama kali, sehingga interaksi tersebut dilakukan pertama kali. Oleh karena itu, karyawan penyedia jasa diharapkan memberikan layanan yang

\footnotetext{
${ }^{4}$ Bakar Resekiani Mas, “Kondisi Pelayanan Dan Kepercayaan Konsumen Pada Service Encounter Dan Service Relationships", Jurnal Scientific Pinisi, (Vol 2 No 2 Tahun 2016)

${ }^{5}$ Rahayu Fatik, "Dampak Service Encounter Quality Terhadap Service Value Evaluation: Studi
}

baik. Jika, penyedia jasa memberikan pelayanan yang baik, maka konsumen mempunyai ketertarikan untuk memakai jasanya. Menurut gutek, bahwa service encountera dalah pertemuan antara konsumen dengan penyedian layanan yang tidak saling kenal.4 Menurut Zeithamel, bahwa service encounter adalah terjadinya interaksi antara konsumen dengan penyediaan jasa.5

Menurut Suprenant, bahwa service encounter sebagai interaksi antara seorang konsumen dengan penyedia jasa.6 Menurut Czepiel, serviceen counter sebagai role performances in which both customer and providers have role to enact.7 Menurut Shostack, service encounter ialah periode waktu dimana konsumen berhubungan dengan perusahaan jasa.8

Jadi, karyawan dan konsumen ialah orang asing yang tidak saling mengetauhi, sehingga interaksi jual beli konsumen dan penyedia jasa dilakukan pertama kali saat itu. Meskipun, interaksi jual beli tersebut dilakukan pertama kali, konsumen mengharapkan layanan yang baik dari penyedia jasa. Oleh karena itu, penyedia jasa diharuskan untuk mewujudkan harapan konsumen.

Pada Higher Education Service", JurnalAkuntasi, (Vol 13 No 3 Tahun 2013)

${ }^{6}$ Ibid

${ }^{7}$ Ibid

${ }^{8}$ Ibid 
Service encounter biasanya disebut sebagai "the moment of truth". ${ }^{9} \mathrm{Hal}$ ini dikarenakan, setiap jasa yang diberikan membutuhkan kehadiran konsumen. Oleh karena itu, perusahaan jasa diharapkan memberikan kesan perusahaan secara keseluruhan. Moment of truth tercipta melalui komitmen yang dibangun oleh karyawan dan konsumen yang memiliki keterikatan. ${ }^{10}$

Jika karyawan mempunyai komitmen yang tinggi pada perusahaan, maka karyawan dapat menciptakan nilai bagi konsumen. Setiap interaksi karyawan perusahaan jasa dengan konsumen membutuhkan sebuah sentuhan. Sentuhan ini dapat berupa "good or bad". Oleh karena itu, dibutuhkan karyawan yang memiliki komitmen tinggi pada perusahaan.

Apabila, perusahaan memberikan pengalaman yang baik dalam melayani konsumen, maka konsumen akan mengingat pengalaman tersebut. Pemberian pengalaman yang baik pada konsumen dapat dengan cara membahagiakan konsumen. Pemberian kebahagiaan konsumen dapat dengan cara memberikan sapaan yang baik serta memberikan sedikit motivasi di akhiran interaksi.

\section{Tahap - tahap Service Encounter}

Menurut Love locktahap service encounter terbagi menjadi tiga tahap, yaitu: ${ }^{11}$

\footnotetext{
${ }^{9}$ Heinonen Kristina, "The Role Of Digital Service Encounters On Customers' Perceptions of Companies", Journal Of Electronic Commerce In Organization, (Vol 6 No 2 Tahun 2008)

${ }^{10}$ Soemarso Embun Duriany, “Analisis Moment of Truth Dalam Membangun Loyalitas Nasabah (Studi Kasus Pada Nasabah Taplus BNI Cabang
}

\section{Tahap Pra-pembelian}

Setiap konsumen selalu menyadari kebutuhan di dalam hidupnya. Di saat, konsumen menyadari kebutuhannya. Konsumen akan cenderung mencari tau kebutuhan yang sesuai dengan keinginanya. Oleh karena itu, konsumen akan mengevaluasi setiap perusahaan pada tahap ini. Konsumen akan mengevaluasi perusahaanperusahaan yang mempunyai produk yang dibutuhkan konsumen. Jadi, konsumen mengevaluasi seluruh perusahaan, agar konsumen tidak merasa menyesal setelah membeli produknya.

\section{Pertemuan Layanan}

Pada situasi ini, interaksi antara konsumen dan karyawan perusahaan terjadi. Oleh karena itu, perusahaan membutuhkan karyawan yang kompeten dalam melayani konsumen. Ketika perusahaan memberikan karyawan yang telah diberikan latihan dalam melayani konsumen, maka konsumen akan menilai pelayanan pada perusahaan. Oleh karena itu, perusahaan diharapkan memberikan keterampilan yang tinggi bagi karyawan perusahan. Karena, saat karyawan memberikan pelayanan yang baik, maka konsumen akan merasa senang.

UNDIP Tembalang Semarang), Jurnal Sains Pemasaran Indonesia, (Vol 9 No 2 Tahun 2010)

${ }^{11}$ Lariwu Stevanus Dan Pangemanan Sifrid, "The Influence Of Service Encounter To Customer Satisfaction At PT Bank BNI (Persero) Tbk, Manado", EconomicManagementBussinesJournal, (Vol 2 No 1 Tahun 2014) 


\section{Pasca Pertemuan}

Setelah melakukan interaksi jual beli, konsumen akan membandingkan perusahaan dengan perusahaan yang lain. Jika konsumen merasakan kepuasan dalam pelayanan yang diberikan perusahaan, maka konsumen akan cenderung mengulang kembali pembeliannya.

\section{Faktor yang mempengaruhi service encounter}

Menurut Parasuraman, faktor pelayanan jasa terbagi menjadi lima faktor, yaitu ${ }^{12}$ :

1. Realibility (kehandalan)

Perusahaan memberikan pelayanan yang maksimal kepada konsumen. Sehingga perusahaan memberikan pelayanan sesuai dengan harapan konsumen, agar konsumen puas dengan pelayanan yang diberikan. Contohnya adalah tepat waktu saat bertemu dengan konsumen, ramah dalam melayani konsumen, memberikan pelayanan sesuai dengan janjinya, dan lain-lain

2. Responsiveness (daya tangkap) Perusahaan memberikan pelayanan yang tidak bertele-tele. Jadi, perusahaan memberikan pelayanan yang cepat, agar konsumen tidak menunggu dengan lama. Karena konsumen akan berfikir negative saat konsumen menunggu tanpa adanya alasan yang jelas. Jika pelayanan tidak sesuai dengan harapan konsumen, maka karyawan mengatasi dengan cara professional sampai konsumen mengubah

\footnotetext{
${ }^{12}$ Aprillia Rio Fathia, "Pengaruh Interpersonal Based Medcal Service Encounters Terhadap Service Quality, Patient Satisfaction And Patient
}

pemikiran negatifnya. Contohnya adalah memberikan diskon saat ada kendala dalam penggunaan jasanya, mengecek terlebih dahulu produknya sebelum memberikan kepada konsumen, merespon dengan baik pendapat ataupun kritikan bagi perusahan, dan lainlain.

3. Assurance (kepastian)

Kemampuan karyawan dalam menumbuhkan rasa percaya pada konsumen. Karyawan diharapkan mampu untuk memahami pengetauhan produk secara cermat dan cepat. Memberikan rasa keamanan bagi konsumen setelah atau sesudah memakai jasanya. Pada faktor assurance tebagi menjadi tiga aspek, yaitu:

1) Keterampilan, yaitu: karyawan memiliki pengetauhan dalam melayani konsumen

2) Kesopanan, yaitu: karyawan melayani dengan ramah kepada konsumen

3) Kredibilitas, yaitu: karyawan memberikan rasa kepercayaan pada konsumen terhadap reputasi perusahaan

4) Keamanan, yaitu: memberikan rasa aman saat berinteraksi

\section{Emphaty (kepedulian)}

Karyawan memahami karakter saat melayani konsumen. karyawan memberikan perhatian yang bersifat individual atau pribadi pada konsumen. Contohnya adalah memberikan kata-kata sugesti (Vol 7 No 1 Tahun 2014) 
diakhir interaksi jual beli dan memberikan kemudahaan saat berinteraksi.

5. Tangible (berwujud)

Produk yang dimiliki perusahaan memiliki bukti fisik nyata. Lingkungan sekitar dapat dijadikan bukti nyata bagi perusahaan jasa. Contohnya adalah Lembaga amil zakat telah diakui negara dengan mempunyai legalitas, perusahaan memiliki bagunan sebagai kantor, memiliki review dari konsumen yang telah memakai jasanya, dan lain-lain

3. Faktor yang menghambat service encounter

Menurut munir, faktor penghambat dalam pelayanan mempunyai enam faktor yaitu ${ }^{13}$ :

1) Karyawan tidak memiliki kesadaran dalam tugas dan kewajiban yang di berikan perusahaan. Jika karyawan tidak menyadari tugas dan kewajibannya, maka karyawan akan melayani sesuka hatinya pada konsumen

2) Perusahaan tidak memberikan sistem prosedur pelayanan pada karyawan

3) Perusahaan tidak mengelola tugas karyawan saat dilapangan dengan baik. Oleh karena itu, banyak terjadinya pelayanan yang belum serasi, sehingga terjadi simpang siur penanganan tugas, tumpang tindih atau tercecernya suatu tugas tidak ada yang menangani.

\footnotetext{
${ }^{13}$ Syahbana Donny, "Pengaruh Lima Dimensi Kualitas Pelayanan Terhadap Kepuasan Anggota Koperasi Susu Warga Mulya Purwobinangun
}

4) Perusahaan tidak memberikan upah yang sesuai dengan kinerjanya. Oleh karena itu, karyawan tidak konsen dalam melayani konsumen karena memikirkan kerja sambilannya

5) Kemampuan karyawan yang tidak mampu dengan tugas yang diberikan perusahaan.

6) Perusahaan tidak memberikan sarana prasarana yang baik pada interaksi konsumen dan karayawan. Oleh karena itu, terjadinya penyelesaian lambat saat transaksi.

\section{Metode Penelitian}

Pendekatan penelititan yang digunakan penulis adalah pendekatan penelitian kualitatif. Pendekatan kualitatif adalah pendeketan penelitian yang tidak dilakukan dengan alatukur dan tanpa adanya manipulasi didalamnya. Jenis penelitian yang digunakan penulis adalah deskriptif. Deskriptif merupakan suatu metode penelitian yang meneliti tentang suatu objek yang bertujuan untuk menggambarkan keadaan pada saat itu secara sistematis, faktual dan akurat. Penelitian ini dilakukan pada kantor Yayasan Nurul Hayat. Kantor Yayasan Nurul Hayat berada di perumahan IKIP gununganyar B-48 Surabaya jawatimur.

\section{Hasil Penelitian dan Pembahasan}

Tahap Service Encounter

1) Tahap Pra pembelian

Setiap konsumen selalu menyadari kebutuhan di dalam hidupnya. Di saat konsumen menyadari kebutuhannya, konsumen akan cenderung mencari tau kebutuhan yang sesuai dengan

Pakem Sleman", Skripsi, (Yogyakarta: Pendidikan Ekonomi Universitas Negeri Yogyakarta 2016) 
keinginanya ${ }^{14}$. Pada tahap ini, Nurul Hayat mengupayakan untuk menjadi produk yang selalu dicari konsumen. Oleh karena itu, Nurul Hayat menggunakan beberapa cara untuk menjadi opsi pertama bagi calon konsumen. Jadi, Nurul Hayat melakukan riset ke pasar khayalak dalam membaca trend-trend yang saat ini berkembang, agar Nurul Hayat mampu bersaing dengan yayasan lainnya. Riset yang dilakukan Nurul hayat menggunakan yang sekiranya menjadi target pasar Nurul Hayat. Adapun beberapa target yang dimilki Nurul Hayat, yaitu: muslim, usia menengah atas, dan yang berpenghasilan tinggi.

Dalam menjadi opsi yang pertama, Nurul Hayat tidak terfokuskan pada konsumennya melainkan fokus pada langkah-langkah inovatifnya. Pada produk sendiri, Nurul Hayat mempunyai tim produksi yang sangat intens untuk menangkap kebutuhan dari konsumen. Nurul hayat mencari tau halhalapa saja yang sekiranya dibutuhkan bagi calon konsumen. Contohnya adalah Nurul Hayat membaca trend saat ini menggunakan makanan middle east. Oleh karena itu, Nurul Hayat mempunyai produk baru untuk masakan aqiqah.

Pada opsi kedua, Nurul Hayat terfokuskan pada digital marketing. Jadi, Nurul Hayat menggunakan digital marketing, agar calon konsumen millenial juga dapat mengakses Nurul Hayat. Selain itu, digital marketing

\footnotetext{
${ }^{14}$ Lariwu Stevanus Dan Pangemanan Sifrid, "The Influence Of Service Encounter To Customer Satisfaction at PT Bank BNI (Persero) Tbk,
}

memudahkan calon konsumen Nurul Hayat mengetahui keberadaan Nurul Hayat. Digital marketing direlasikan berupa website dan sosial media. Website Nurul Hayat sendiri dibentuk sesuai dengan standart Nurul Hayat. Standart yang digunakan Nurul Hayat adalah bagus tampilannya, informatif, dan mudah diakses. Bagus ini dikategorikan menarik secara penampilan. Jadi, Nurul Hayat membuat website tersebut semenarik mungkin, agar calon konsumen merasa senang mengakses website Nurul Hayat. Website Nurul Hayat membuat website dengan mudah diakses, karena kebanyakan pengguna internet aksesnya itu menggunakan handphone. Oleh karena itu, Nurul Hayat mengharapkan website yang dimiliki mobile friendly. Opsi kedua, Nurul Hayat mengarahkan konsumen yang telah menggunakan nurul hayat untuk memberikan review di google review. Jadi, Nurul Hayat meminta konsumen yang telah menggunakan produknya untuk memberikan review di google review, agar calon konsumen dapat melihat sepak terjang yang dimiliki Nurul Hayat. Selain itu, Nurul Hayat mengandalkan endorse pada public figure. Hal ini diharapkan, calon konsumen semakin tertarik mencoba produk Nurul Hayat.

Pada opsi terakhir, Nurul Hayat mempunyai segment pasar yang cenderung tidak menyukai interaksi online. Nurul hayat memberikan kemudahan bagi calon konsumen yang 
tidak terlalu menyukai interaksi online. Jadi, Nurul Hayat menghadirkan birobiro Nurul Hayat, agar calon konsumen tidak diberatkan dengan lokasi yang jauh dari kediaman konsumen. Selain itu, Nurul Hayat selalu menyiapkan brosur-brosur bagi konsumen.

Dengan demikian, Nurul Hayat mempunyai trik untuk menjadi opsi pertama untuk digunakan oleh calon pembelian. Menurut narasumbernarasumber Nurul Hayat, Nurul Hayat selalu melakukan riset pada pasar untuk membaca trend-trend yang saat ini berkembang. Selain itu, Nurul Hayat juga mengupayakan digital marketing. Jadi, Nurul Hayat membuat website dan sosial media sebagai salah satu pemasaran, agar konsumen dapat merasakan kemudahan akses untuk melakukan riset. Nurul Hayat juga memudahkan bagi calon konsumen yang lebih menyukai interaksi langsung terhadap Nurul Hayat. Oleh karena itu, Nurul Hayat mendirikan biro-biro yang tersebar di seluruh kota. Jika, biro-biro Nurul Hayat tersebar seluruh kota, maka konsumen tidak akan merasakan kesulitan untuk menjangkau kantor pusat ataupun cabang Nurul Hayat.

Menurut penulis, tahap pra pembelian Nurul Hayat sama dengan teori pra pembelian. Hal ini dikarenakan, Nurul Hayat selalu berupaya untuk memberikan produk yang sesuai keinginan calon pembeli. Selain itu, Nurul Hayat juga mengupayakan untuk selalu update perkembangan yang saat ini terjadi pada pasar Nurul Hayat. Hal ini selaras

${ }^{15}$ Lariwu Stevanus Dan Pangemanan Sifrid, "The Influence Of Service Encounter To Customer Satisfaction At PT Bank BNI (Persero) Tbk, dengan teori tahap pra pembelian. Di saat, konsumen menyadari kebutuhan nya, konsumen akan cenderung mencari tau kebutuhan yang sesuai dengan keinginanya ${ }^{15}$

\section{Tahap Service Encounter}

Pada tahap service encounter, interaksi antara konsumen dan karyawan terjadi. Perusahaan membutuhkan karyawan yang kompeten dalam melayani konsumen $^{16}$. Adapun beberpa proses terjadinya interaksi karyawan Nurul Hayat dengan konsumennya. Awal kedatangan konsum-en, karyawan akan memberikan salam serta memperkenalkan diri. Setelah itu, karyawan akan meminta konsumen untuk duduk. Pada saat duduk, karyawan akan menanyakan keperluan konsumen.

Setelah konsumen mengatakan keperluannya, kar-yawan otomatis akan memberikan gambaran-gambaran produk yang diminta konsumen. Oleh karena itu, sesi tersebut membutuhkan karyawan yang kompeten yang memilki product knowledge. Jika konsumen telah setuju dengan segala penawaran dari karyawan, maka karyawan akan melakukan proses input. Pada proses input data, karyawan akan mengisi data-data yang sekiranya dibutuhkan untuk memperlancar interaksi jual beli. Setelah melakukan input data, data yang telah diisiakan diprint oleh pihak karyawan Nurul Hayat. Pada proses ini, konsumen akan meng crosscheck data.

Jadi, konsumen akan mengecek datadata yang telah di isi karyawan, agar tidak terjadinya kesalahan pada interaksi selanjutnya. Selanjutnya, proses pembayaran. Pembayaran produk dapat dilakukan melalui debit, tunai, ataupun transfer. Pembayaran aqiqah dapat dilakukan 50\% di awal dan pelunasan di hari pengiriman. Setelah itu, karyawan akan memberikan

Manado", EconomicManagementBussinesJournal, (Vol 2 No 1 Tahun 2014)

${ }^{16}$ Ibid 
kwitansi bagi konsumen. Kwitansi ini diharapkan akan dijaga oleh konsumen. Oleh karena itu, karyawan Nurul Hayat selalu mewanti-wanti untuk menjaga kwintasi tersebut.

Di akhir interaksi, karyawan diwajibkan untuk melakukan cross selling dan up selling. Cross selling disini karyawan menawarkan produk yang lain selain produk yang awal ingin dibeli. Misalkan, konsumen melakukan interaksi aqiqah, maka akhir interaksi karyawan akan menawarkan produk herbal. Jika up selling karyawan hanya memberikan penawaran yang sesuai dengan interaksi awal, maka produk yang dimiliki konsmen akan lebih baik. Misalkan, konsumen melakukan interaksi aqiqah, maka karyawan menawarkan tentang tempat makan yang lebih baik ataupun tas tenteng berlogo Nurul Hayat.

Proses interaksi online mempunyai kesamaan dengan proses interaksi offline. Hal yang membedakan interaksi online dan offline adalah pada interaksi online karyawan akan mengirim gambar-gambar digital brosur tentang Nurul Hayat. Selain itu, Nurul Hayat mempunyai interaksi konsumen dan karyawan pada haji dan umroh mempunyai perbedaan dari ineteraksi jual belil ainnya. Perusahaan memberikan karyawan yang telah diberikan latihan dalam melayani konsumen ${ }^{17}$. Pada interaksi haji dan umroh, Nurul Hayat mempunyai tim sendiri untuk langsung menjelaskan produknya di rumah konsumen. Jadi, Nurul Hayat akan mengirim tim yang mempunyai pengetauhan product knowledge haji dan umroh, agar konsumen dapat melakukan interaksi lebih intim.

Dalam meyakinkan konsumen, karyawan dituntut untuk memiliki engetauhan dalam marketing. Oleh karena itu, karyawan selalu menawarkan produk

\footnotetext{
${ }^{17}$ Ibid

${ }^{18}$ Lariwu Stevanus Dan Pangemanan Sifrid, "The Influence Of Service Encounter To Customer
}

sesuai dengan pawakan konsumen. Selain itu, karyawan juga diharapkan bertutur kata lembut pada interaksi jual belinya. Nurul Hayat telah berdiri dari tahun 2011. Oleh karena itu, beberapa karyawan selalu menjelaskan pada calon konsumen dengan memberikan review yang telah mereka terima dari konsumen sebelumnya. Hal ini diharapkan, calon konsumen semakin yakin dengan amanah yang diberikan Nurul Hayat.

Penawaran yang diberikan Nurul Hayat dilakukan dengan voucher ataupun promo-promo. Jadi, Nurul Hayat selalu memberikan promo ataupun voucher menarik di setiap kesempatan, agar konsumen selalu tertarik untuk terus berinteraksi. Promo yang diberikan biasanya melalui sms lewat no pribadi konsumen. Selain itu, Nurul Hayat juga memberikan voucher lewat aplikasi $e$ commerce. Nurul Hayat juga selalu hadir untuk memberikan diskon pada hari besar islam.

Dalam hal ini dapat disimpulkan, proses interaksi service encounter pada Nurul Hayat memasksimalkan pelayanan. Jika Nurul Hayat memberikan pelayanan yang dapat memuaskan konsumen, maka konsumen akan merasa senang berinteraksi di Nurul Hayat. Menurut peneliti, teori pertemuan layanan yang ada sejalan oleh Nurul Hayat. Hal ini dibuktikan, Nurul Hayat selalu mengupayakan agar konsumen merasa puas saat berinteraksi. Jika perusahaan memberikan keterampilan yang tinggi bagi karyawan perusahan, maka karyawan memberikan pelayanan yang baik untuk menyenangkan konsumen. ${ }^{18}$

\section{Tahap Pasca Pembelian}

Setelah melakukan interaksi jual beli, konsumen akan membandingkan perusah-

Satisfaction At PT Bank BNI (Persero) Tbk, Manado", Economi Management Bussines Journal, (Vol 2 No 1 Tahun 2014) 
aan dengan perusahaan yang lain ${ }^{19}$. Pada pasca pembelian, loyalitas konsumen dapat dinilai. Manakala konsumen loyal kepada Nurul Hayat, maka karyawan telah memberikan pelayanan yang baik. Sebanyak $60 \%$ lebih konsumen menjadi konsumen tetap di Nurul Hayat. Alasan konsumen tetap menggunakan jasa Nurul Hayat antara lain: turun temurun dan telah cocok dengan produk ataupun pelayanan yang diberikan oleh Nurul Hayat. Oleh karena itu, setiap bulannya terdapat konsumen tetap yang telah melakukan interaksi pada Nurul Hayat.

Narasumber-narasumber mengatakan hal hal yang sekiranya dapat mempertahankan konsumen untuk terus menggunakan produk Nurul Hayat. Hal pertama yaitu menjaga kualitas produk maupun pelayanan. Oleh karena itu, disetiap akhir interaksi karyawan Nurul Hayat telah memberikan education bahwa setelah berakhirnya interasksi akan ada tim yang memberikan link ataupun sms berisi tentang penilaian terhadap Nurul Hayat. Pada penilaian, Nurul Hayat menerima seluruh masukan dari Nurul Hayat. Setelah menerima, Nurul Hayat akan mengkaji lebih dalam mana yang akan diperbaiki pada pelayanan Nurul Hayat.

Hal ini diharapkan, setelah konsumen keluar dari Nurul Hayat konsumen akan merasa sangat puas. Hal kedua yaitu selalu menjaga komunikasi antara kosumen dan Nurul Hayat. Nurul Hayat cenderung akan merawat konsumen untuk terus tertarik dengan produk Nurul Hayat. Oleh karena itu, setelah konsumen mendatangi Nurul Hayat. Nurul Hayat tidak akan melepaskan komunikasi pada konsumennya. Nurul Hayat mempunyai trik unik dalam merawat kosumen. Trik tersebut adalah Nurul Hayat

\footnotetext{
${ }^{19}$ Ibid

${ }^{20}$ Lariwu Stevanus Dan Pangemanan Sifrid, "The Influence Of Service Encounter To Customer Satisfaction At Pt Bank Bni (Persero) Tbk, Manado", EconomicManagementBussinesJournal, (Vol 2 No 1 Tahun 2014)
}

selalu memberikan ucapan doa bagi konsumen yang sedang berulang tahun.

Menurut penulis, Nurul Hayat berusaha supaya konsumen selalu merasa puas. Hal ini diharapkan, konsumen akan selalu menggunakan jasa Nurul Hayat. Jika, konsumen merasakan kepuasan dalam pelayanan yang diberikan perusahaan, maka konsumen akan cenderung mengulang kembali pembeliannya. ${ }^{20}$ Nurul Hayat telah melakukan hal-hal yang sejalan dengan teori pasca pembelian. Pada teori, konsumen diharapkan untuk selalu mengulang pembeliannya. Oleh karena itu, Nurul Hayat selalu menjaga komunikasi pada konsumen yang telah menggunakan jasanya. Hal ini diharapkan, konsumen akan mengulang pembelian produknya

\section{Faktor yang mempengaruhi}

\section{1) Reability}

Perusahaan harus memberikan pelayanan yang maksimal kepada konsumen ${ }^{21}$. Oleh karena itu, Nurul Hayat perlu menyusun SOP untuk pelayanan pada konsumen. Pada SOP cs, Nurul Hayat menetapkan garis besarnya adalah ramah. Karyawan dituntut untuk selalu ramah dan tersenyum dalam melayani konsumen. Hal ini diharapkan, konsumen akan merasakan nyaman saat berinteraksi dengan karyawan. Nurul Hayat juga mempunyai SOP pada bagian telphone ataupun online. Garis besar pada SOP telp atau pun online adalah intonasi perkataan yang diharuskan ramah. SOP yang dimiliki Nurul Hayat berguna untuk memastikan pelayanan yang dimiliki sama. Jadi,

\footnotetext{
${ }^{21}$ Fathia Aprillia Rio Fathia, "Pengaruh Interpersonal Based Medcal Service Encounters Terhadap Service Quality, Patient Satisfaction And Patient Trust", Jurnal Manajemen Dan Pemasaran Jasa, (Vol 7 No 1 Tahun 2014)
} 
pelayanan kantor cabang ataupun pusat

Nurul Hayat mempunyai kesamaan dalam melayani, agar konsumen selalu merasa puas dengan pelayanan yang diberikan Nurul Hayat. Jika, konsumen puas pada pelayanan Nurul Hayat, maka konsumen akan merasa nyaman berinteraksi di Nurul Hayat. Selain itu, SOP cs diwajibkan untuk selalu cross selling dan up selling.

Nurul Hayat ialah salah satuyayasan yang pengawasan terhadap SOP sangatketat. SOP yang dibuat oleh Nurul Hayat diwajibkan untuk dipatuhi oleh seluruh karyawan. Oleh karena itu, Nurul Hayat mempunyai KPI (Key Performance Indikator) sebagai pengukur kinerja karyawan. Setiap bulannya, karyawan Nurul Hayat akan mendapatkan form-form terkait dengan penilaian. Penilaian tersebut berupa berapa persen SOP yang telah dijalankan karyawan. Setiap karyawan yang akan melayani konsumen

Menurut peneliti, faktor reability yang digunakan oleh Nurul Hayat sama dengan standart teori. Hal ini dikarenakan, Nurul Hayat menggunakan SOP sebagai landasan karyawan Nurul Hayat dalam melayani konsumen. Jika, perusahaan memberikan pelayanan sesuai dengan harapan konsumen, maka konsumen puas dengan pelayanan yang diberikan ${ }^{22}$. Nurul Hayat juga memilikidevisi yang telahmengatur SOP karyawan. Jadi, Nurul Hayat mempunyai tim khusus dalam memantau karyawan pada sopnya, agar

\footnotetext{
${ }^{22}$ Fathia Aprillia Rio Fathia, "Pengaruh Interpersonal Based Medcal Service EncountersTerhadapService Quality, Patient
}

karyawan selalu mematuhi SOP yang telah dibuat Nurul Hayat.

2) Responsiveness

Pada faktor responsiveness ialah faktor dalam menangani adanya kesalahan dalam melayani konsumen. Pada saat interaksi konsumen dan karyawan, karyawan diharapkan untuk selalu memeberikan pelayanan yang prima. Oleh karena itu, Nurul Hayat selalu memberikan kesederhanaan pada setiap interaksi jual belinya. Meskipun Nurul Hayat mengharapkan tidak ada kendala sama sekali pada interaksi, kenyataannya selalu ada kendala pada setiap interaksi jual beli. Oleh karena itu, Nurul Hayat sellau mengupayakan untuk selalu menangani kedala dengan sebaik mungkin. Di setiap adanya kendala dalam interaksi, Nurul Hayat tidak serta merta akan menyalahkan karyawan. Nurul Hayat akan cenderung untuk mencari tau kejadian yang terjadi hingga keakar-akarnya. Jika Nurul Hayat telah menemukan kesalahan pada kejadian kendala tersebut, maka Nurul Hayat akan mencari solusinya. Jika kesalahan ada pada Nurul Hayat, Nurul Hayat akan meminta maaf langsung dan mengganti kerugian yang telah terjadi. Nurul Hayat mempunyai call center yang beroperasi dari jam 8.00 pagi hingga 20.00 malam. Hal ini diharapkan, Nurul Hayat dapat menangani langsung saat terjadinya kendala. Menurut penulis, bahwa hal yang dilakukan Nurul Hayat sama dengan teori responsiveness. Nurul Hayat menyediakan call center bagi

Satisfaction and Patient Trust", JurnalManajemen Dan Pemasaran Jasa, (Vol 7 No 1 Tahun 2014) 
konsumen yang ingin menyampaikan aduan. Jika pelayanan tidak sesuai dengan harapan konsumen, maka karyawan mengatasi dengan cara professional sampai konsumen mengubah pemikiran negatifnya ${ }^{23}$. Nurul Hayat selalu mengupayakan setiap permasalahan yang telah diadukan konsumen akan selesai dengan cepat. Jadi, konsumen tidak merasakan diabaikan saat adanya permasalahan, agar konsumen tidak berfikir negatif pada Nurul Hayat.

\section{3) Assurance}

Pada faktor assurance terbagi menjadi aspek. Aspek pertama adalah keterampilan. Keterampilan disini yang dimaksud adalah karyawan memiliki pengetauhan dalam melayani konsumen. Sebelum Nurul Hayat menetapkan calon karyawan di devisi. Nurul Hayat selalu menyeleksi calon karyawan terlebih dahulu. Setelah ditetapkan di sebuah devisi, Nurul Hayat selalu memberikan training terlebih dahulu.

Training yang diberikan biasanya selama 1-3 bulan. Selain itu, Nurul Hayat juga mewajibkan karyawan terutama bagian cs untuk menghafal product knowledge yang dimiliki Nurul Hayat. Nurul Hayat juga menetapkan bagi seluruh custumor service untuk mempunyai buku tentang product knowledge Nurul Hayat. Jika Nurul Hayat mempunyai produk yang baru, maka karyawan custumor service akan diberikan briefing tentang produk baru tersebut.

\footnotetext{
${ }^{23} \mathrm{Ibid}$

${ }^{24}$ Fathia Aprillia Rio Fathia, "Pengaruh Interpersonal Based Medcal Service EncountersTerhadapService Quality, Patient
}

Aspek kedua adalah kesopanan. Karyawan diharapkan untuk melayani konsumen dengan ramah $^{24}$. Sesuai dengan bahasan peneliti sebelumnya, Nurul Hayat mewajibkan karyawan untuk mematuhi SOP yang diberikan. SOP yang dimilki Nurul Hayat juga dikatakan bahwa karyawan diharuskan untuk ramah dan selalu tersenyum pada konsumen. Jika karyawan tidak memenuhi standart SOP Nurul Hayat, maka karyawan akan mendapatkan surat peringatan.

Aspek ketiga adalah kredibilitas. Karyawan memberikan rasa kepercayaan pada konsumen terhadap reputasi perusahaan ${ }^{25}$. Nurul Hayat telah berdiri dari tahun 2001. Selain itu, laba dari Nurul Hayat sebagian besar akan diberikan kepada anak yatim. Oleh karena itu, Nurul Hayat selalu menjaga amanahnya. Hal ini dikarenakan, Nurul Hayat tidak ingin mengkorbankan anak yatim.

Aspek terakhir adalah keamanan. Perusahaan memberikan rasa aman saat berinteraksi ${ }^{26}$. Nurul Hayat selalu berusaha untuk menjaga keamanan data-data konsumen. Nurul Hayat selalu memusnahkan berkas-berkas konsumen yang telah lama berinteraksi. Selain itu, pada produk Nurul Hayat kreatif. Karyawan akan menanyakan terlebih dahulu apakah produknya dapat di duplikat untuk contoh bagi caon konsumen yang akan datang.

Menurut penulis, faktor assurance yang dimilki Nurul Hayat sejalan dengan

Satisfaction And Patient Trust", JurnalManajemen Dan Pemasaran Jasa, (Vol 7 No 1 Tahun 2014)

${ }^{25}$ Ibid

${ }^{26}$ Ibid 
keempat aspek assurance. Keempat aspek tersebut telah dipenuhi oleh Nurul Hayat. Pada aspek pertama yaitu: keterampilan. Nurul Hayat memberikan training bagi karyawan baru. Setelah itu Nurul Hayat juga memberikan buku product knowledge untuk dihafalkan. Pada aspek kedua yaitu kesopanan. Pada aspek kesopanan, Nurul Hayat mewajibkan custumor service untuk selalu ramah dan tersenyum dalam interaksi antara konsumen dan karyawan. Pada aspek ketiga yaitu: kepercayaan. Aspek kepercayaan ialah aspek yang dijunjung tinggi oleh Nurul Hayat. Nurul Hayat mengupayakan untuk sellau amanah dalam mengelola uang yang telah diberikan Nurul Hayat. Aspek terakhir adalah keamanan. Pada aspek terakhir, Nurul Hayat mengupayakan data-data konsumen untuk terjamin dengan keamanannya,

4) Emphaty

Pada faktor emphaty dibutuhkan karyawan yang memahami karakter setiap konsumen yang datang. Karyawan diharapkan dapat menyesuaikan setiap konsumen yang datang. Nurul Hayat mewajibkan karyawan cs untuk menghafal nama konsumen yang sedang berinteraksi dengan karyawan. Jadi, diawal interaksi hingga akhir interaksi karyawan diharuskan hafal dengan nama konsumen, maka konsumen akan merasa nyaman berinteraksi dengan karyawan. Disetiap akhiri nteraksi, karyawan Nurul Hayat selalu mendoakan konsumen yang telah

\footnotetext{
${ }^{27}$ Ibid

${ }^{28}$ Fathia Aprillia Rio Fathia, "Pengaruh Interpersonal Based Medcal Service Encounters Terhadap Service Quality, Patient Satisfaction And
}

berinteraksi. Hal ini sejalan dengan terapan teori emphaty. Karyawan memberikan perhatian yang bersifat individual atau pribadi pada konsumen $^{27}$

5) Tangible

Faktor tangible ialah faktor yang mempunyai bukti fisik pada suatu perusahaan $^{28}$. Nurul Hayat sendiri telah mempunyai gedung. Oleh karena itu, peneliti mencari bukti tentang review yang dimilki Nurul Hayat. Review yang dimiliki Nurul Hayat lebih diutamakan review di google review. Tetapi tidak menutup kemungkinan, Nurul Hayat juga meminta review sendiri untuk perkembangan Nurul Hayat. Karyawan Nurul Hayat selalu memberikan informasi bahwa, setelah melakukan interaksi Nurul Hayat mempunyai tim yang akan menanyakan tentang perihal layanan yang didapat. Nilai yang disediakan Nurul Hayat adalah 1-5. Lima ialah nilai yang paling memuaskan. Menurut penulis, teori tangible telah sejalan dengan kenyataan yang ada di Nurul Hayat. Nurul Hayat mempunyai gedung pusat dan cabangcabangnya. Selain itu, Nurul Hayat selalu meminta review konsumen yang telah menggunakan produknya.

\section{Faktor Penghambat}

Faktor penghambat mempunyai enam aspek. Pada aspek pertama adalah Karyawan tidak memiliki kesadaran dalam tugas dan kewajiban yang di berikan perusahaan ${ }^{29}$. Para karyawan-

Patient Trust", JurnalManajemen Dan Pemasaran Jasa, (Vol 7 No 1 Tahun 2014)

${ }^{29}$ Syahbana Donny, "Pengaruh Lima Dimensi Kualitas Pelayanan Terhadap Kepuasan Anggota 
nya Nurul Hayat mempunyai keunikan tersendiri. Rata-rata karyawan Nurul Hayat mempunyai pemikiran bahwa, karyawan Nurul Hayat tidak mencari uang tetapi mengabdi pada umat. Oleh karena itu, setiap karyawan memiliki jiwa kepemilikan yang tinggi pada Nurul Hayat. Karyawan Nurul Hayat berfikir, bahwa mereka bekerja untuk melayani umat. Karyawan Nurul Hayat rata-rata sering mendapatkan teguran entah dari kesalahan kecil maupun besar. Tetapi, karyawan Nurul Hayat tidak pernah mempermasalahkan tersebut, karyawan Nurul Hayat cenderung menganggap terguran tersebut sebagai nasehat baik.

Asper kedua adalah Perusahaan tidak memberikan sistem prosedur pelayanan pada karyawan ${ }^{30}$. Sistem prosedur pelayanan yang dimiliki Nurul Hayat ialah sesuai dengan SOP yang dimiliki. Salah satu SOP Nurul Hayat dulunya, yaitu: diwajibkan untuk berbicara bahasa Indonesia di setiap transaksi. Tetapi, SOP bahasa tersebut telah di ganti, karayawan dapat menyesuaikan bahasa dari konsumen. Hal ini dikarenakan, SOP bahasa dianggap memberikan jarak antara konsumen dan karyawan yang sedang bertransaksi. Tetapi, bahasa yang digunakan karyawan ialah bahasa yang sopan. Oleh karena itu, karyawan Nurul Hayat selalu mengupayakan untuk menyesuaikan konsumen yang datang pada Nurul Hayat. Menyesuaikan tersebut dapat berupa

Koperasi Susu Warga Mulya Purwobinangun Pakem Sleman", Skripsi, (Yogyakarta: Pendidikan Ekonomi Universitas Negeri Yogyakarta 2016)

${ }^{30} \mathrm{Ibid}$

${ }^{31}$ Ibid dari bahasa ataupun transaksinya. Jadi, karyawan menyesuaikan tawaran yang diberikan sesuai dengan kemampuan transaksi konsumen, agar konsumen tidak merasa terbebani.

Aspek ketiga adalah Perusahaan tidak mengelola tugas karyawan saat di lapangan dengan baik $^{31}$. Jika, Nurul Hayat tidak mengelolan tugas karyawan dilapangan dengan baik, maka pekerjaan karyawan akan terbengkalai. Hal ini menyebabkan, pekerjaaan karyawan akan terjadinya tumpang tindih, simpang siur, ataupun tidak sesuai dengan SOP Nurul Hayat. Oleh karena itu, Nurul Hayat perlu memantau karyawan dalam bekerja. Nurul Hayat selalu memantau pekerjaan karyawan melalui CCTV. Jadi, Nurul Hayat selalu memantau karywan melalui CCTV yang aktif selama 24 jam, apalagi CCTV yang dimiliki Nurul Hayat juga dapat merekam suara.

Aspek keempat adalah perusahaan tidak memberikan upah yang sesuai dengan kinerjanya ${ }^{32}$. Pada fase ini, karyawan akan mencari kerja sambilan. Di Nurul Hayat karyawan yang memiliki kerja sambilan lumayan banyak. Selain itu, ada beberapa karyawan yang kuliah. Tetapi, Nurul Hayat dalam menyikapi karyawan yang memiliki kerja sambilan, karyawan tidak diperbolehkan untuk bekerja sambilan pada jam efektif kantor Nurul Hayat. Jika karyawan melanggar peraturan tersebut,
${ }^{32}$ Syahbana Donny, "Pengaruh Lima Dimensi Kualitas Pelayanan Terhadap Kepuasan Anggota Koperasi Susu Warga Mulya Purwobinangun Pakem Sleman", Skripsi, (Yogyakarta: Pendidikan Ekonomi Universitas Negeri Yogyakarta 2016) 
karyawan akan ditegur oleh bagian HRD.

Aspek kelima adalah kemampuan karyawan yang tidak mampu dengan tugas yang diberikan perusahaan ${ }^{33}$. Pada saat rekruitment, pertanyaan yang sering diberikan HRD adalah apakah mampu dan mau dengan segala job disk maupun peraturan Nurul Hayat. Jika calon karyawan menyanggupi segala tuntutan yang diberikan Nurul Hayat, maka devisi HRD akan memasukan ke devisi yang sesuai dengan bidang yang sesuai dari calon karyawan. Karyawan yang akan menjadi karyawan tetap Nurul Hayat akan diberikan training selama 1-3 bulan. Pada saat training, calon karywan akan dipantau oleh Nurul Hayat. Jika karyawan cocok di devisi yang dituju, maka dia akan diangkat menajdi karyawan tetap. Jika, karyawan tidak sesuai di suatu devisi yang telah disiapkan, maka karyawan akn dipindahkan ke devisi yang sekiranya sesuai dengan karyawan.

Aspek terakhir adalah perusahaan tidak memberikan sarana prasarana yang baik pada interaksi konsumen dan karayawan $^{34}$. Kantor pusat yang dimiliki Nurul Hayat mempunyai dua gedung. Gedung yang pertama ialah gedung utama yang beroperasi lebih intent. Gedung yang kedua ialah gedung yang beroperasi hanya untuk devisi program, NH kreatif, dan BMT. Kedua gedung pusat tersebut mempunyai sarana dan prasarana yang berbeda. Gedung yang pertama lebih banyak menampung konsumen. Karena kebanyakan interaksi jual beli Nurul

${ }^{33}$ Ibid
Hayat dilakukan di gedung pertama. Oleh karena itu, fasilitas yang diberikan sangat cukup. Nurul Hayat mempunyai form pengajuan khusus untuk sarana dan prasarana. Jika karyawan mengajukan form pengajuan, maka barang yang diminta besoknya akan ditangani. Tetapi, gedung kedua tidak terlalu memadahi prasarananya. Gedung kedua tidak disediakan air putih bagi konsumen. Selain itu, gedung kedua tidak diberikan kamar mandi khusus bagi konsumen. Tetapi, sarana dana prasarana yang diberikan nh kreatif cukup memadahi, Nurul Hayat menyediakan kamera untuk video dan foto, serta laptop yang mempunyai standart dalam pengeditan.

Menurut penulis, Nurul Hayat dapat menyelesaikan hal-hal yang menjadi faktor penghambat. Dari ke enam aspek faktor penghambat, hanya dua aspek yang kurang memadai. Tetapi, Nurul Hayat mempunyai penyelesaian dalam menangani faktor-faktor yang menjadi penghambat.

\section{Kesimpulan}

Berdasarkan dari pembahasan analisis data pada bab sebelumnya, maka penelitidapat mengambil kesimpulan sebagai berikut:

1) Penerapan service encounter yang di Nurul Hayat terdapat tiga tahap. Pertama, Nurul Hayat selalu mengupayakan untuk selalu update perkembangan yang saat ini terjadi pada pasar sasaran. Nurul Hayat berupaya memenuhi permintaan konsumen yang saat ini berkembang. Kedua, dalam interaksi jual beli dengan konsumen, 
Nurul Hayat selalu berupaya memberikan pelayanan yang ramah dan maksimal dengan senantiasa memberikan semua yang konsumen minta dengan tujuan membuat konsumen senang terhadap pelayanan yang diberikan. Di setiap akhir interaksi, karyawan Nurul Hayat selalu melakukan cross selling dan up selling. Ketiga, merawat konsumen dengan memberikan promo, voucher, ucapan selamat, dan informasi seputar produk Nurul Hayat.

2) Faktor pendukung service encounter di Nurul Hayat, yaitu:

a) Nurul Hayat menggunakan SOP sebagai landasan karyawan Nurul Hayat dalam melayani konsumen.

b) Nurul Hayat mempunyai tim khusus dalam memantau karyawan pada SOPnya, agar karyawan selalu mematuhi SOP yang telah dibuat Nurul Hayat.

c) Nurul Hayat menyediakan call center bagi konsumen yang ingin menyampaikan aduan.

d) Nurul Hayat selalu mengupayakan setiap permasalahan yang telah di adukan konsumen akan selesai dengan cepat.

e) Nurul Hayat memberikan training bagi karyawan baru.

f) Nurul Hayat memberikan buku product knowledge untuk dihafalkan.

g) Nurul Hayat mewajibkan custumor service untuk selalu ramah

h) Nurul Hayat mengupayakan untuk selalu amanah dalam mengelola uang yang telah diberikan konsumen

i) Nurul Hayat menjamin data-data konsumen. j) Karyawan mampu menyesuaikan diri terhadap setiap konsumen yang datang.

k) Nurul Hayat mewajibkan karyawan cs untuk menghafal nama konsumen yang sedang berinteraksi dengan karyawan.

1) Nurul Hayat telah mempunyai bukti nyata gedung dan review dari konsumen yang telah menggunakan jasanya.

3) Faktor penghambat, service encounter di Nurul Hayat, yaitu:

a) Karyawan mempunyai kerja sambilan yang bisa mempengaruhi pelayanan.

b) Salah satu gedung utama tidak memadai dalam melayani konsumen

\section{Daftar Pustaka}

Lubis Alfi Syahri dan Andayani Nur Rahma, "Pengaruh Kualitas Pelayanan (Service Quality) Terhadap Kepuasan Pelanggan PT Sucofindo Batam", Business Administration, (Vol 1 No 2 Tahun 2017)

Panjaitan Effendi Januar Dan Yuliati Ai Lili, "Pengauh Kualitas Pelayanan Terhadap Kepuasan pelanggan pada JNE cabang Bandung", Vol 1 No 2 Tahun 2016)

Putri Yulia Larasati Dan Utomo Hardi, "Pengaruh Kualitas Pelayanan Terhadap Loyalitas Pelanggan Dengan Kepuasan Sebagai Variable Intervening (Studi Presepsi Pada Pelanggan Dian Corp Ambarawa), Jurnal Manajemen, (Vol 10 No 19 Tahun 2017).

Bakar Resekiani Mas, "Kondisi Pelayanan Dan Kepercayaan Konsumen Pada 
Service Encounter Dan Service Relationships", Jurnal Scientific Pinisi, (Vol 2 No 2 Tahun 2016)

Rahayu Fatik, "Dampak Service Encounter Quality Terhadap Service Value Evaluation: Studi Pada Higher Education Service", JurnalAkuntasi, (Vol 13 No 3 Tahun 2013)

Lariwu Stevanus Dan Pangemanan Sifrid, "The Influence Of Service Encounter To Customer Satisfaction At PT Bank BNI (Persero) Tbk, Manado", Economic Management Bussines Journal, (Vol 2 No 1 Tahun 2014)

Soemarso Embun Duriany, "Analisis Moment Of Truth Dalam Membangun Loyalitas Nasabah (Studi Kasus Pada Nasabah Taplus BNI Cabang UNDIP Tembalang Semarang), Jurnal Sains Pemasaran Indonesia, (Vol 9 No 2 Tahun 2010)

Heinonen Kristina, "The Role Of Digital Service Encounters On Customers' Perceptions Of Companies", Journal Of Electronic Commerce In Organization, (Vol 6 No 2 Tahun 2008)

Aprillia Rio Fathia, "Pengaruh Interpersonal Based Medcal Service Encounters Terhadap Service Quality, Patient Satisfaction And Patient Trust", Jurnal Manajemen Dan Pemasaran Jasa, (Vol 7 No 1 Tahun 2014)

Syahbana Donny, "Pengaruh Lima Dimensi Kualitas Pelayanan Terhadap Kepuasan Anggota Koperasi Susu Warga Mulya Purwobinangun Pakem Sleman", Skripsi, (Yogyakarta: Pendidikan Ekonomi Universitas Negeri Yogyakarta 2016)
Lariwu Stevanus Dan Pangemanan Sifrid, "The Influence Of Service Encounter To Customer Satisfaction at PT Bank BNI (Persero) Tbk, Manado", Economic Management Bussines Journal, (Vol 2 No 1 Tahun 2014)

Fathia Aprillia Rio Fathia, "Pengaruh Interpersonal Based Medcal Service Encounters Terhadap Service Quality, Patient Satisfaction And Patient Trust", Jurnal Manajemen Dan Pemasaran Jasa, (Vol 7 No 1 Tahun 2014) 